\title{
COMPETITIVIDADE NO SETOR AUTOMOBILÍSTICO: UM MODELO DE ANÁLISE DA FLEXIBILIDADE NO BRASIL
}

\section{COMPETITIVITY IN THE AUTOMOTIVE SECTOR: A MODEL OF ANALYSIS OF FLEXIBILITY IN BRAZIL}

\author{
Rejane Prevot Nascimento ${ }^{1}$, Lidia Micaela Segre ${ }^{2}$ \\ ${ }^{1}$ Universidade do Grande Rio - UNIGRANRIO - Rio de Janeiro - Brasil rejaneprevot@uol.com.br \\ ${ }^{2}$ Universidade do Grande Rio -UNIGRANRIO - Rio de Janeiro - Brasil \\ micaela@ms.microlink.com.br
}

\begin{abstract}
Resumo
O objetivo deste trabalho é analisar a flexibilidade no setor automobilístico brasileiro, com base em estudos de caso de três plantas. A partir destes estudos verifica-se que a obtenção da flexibilidade está mais associada aos fatores organizacionais do que aos fatores tecnológicos. Apresenta-se ainda um modelo de análise que enfoca as variáveis da flexibilidade nas empresas deste setor, classificadas em duas categorias: internas e externas. O estudo das empresas, a partir do modelo proposto, mostra que o contexto brasileiro oferece condições ótimas para a implantação de um tipo de fábricas automobilísticas com perfil predominante de montadoras, que obtém flexibilidade sem que haja uma obrigação legal de investimento em tecnologia e de difusão de conhecimento. A metodologia utilizada neste trabalho abrange levantamento bibliográfico nacional e internacional e pesquisa de campo, realizada por meio de entrevistas com funcionários de diferentes níveis, observação participante e análise dos documentos das empresas.
\end{abstract}

Palavras chaves: setor automobilístico brasileiro, flexibilidade, relações de trabalho, flexibilidade externa, flexibilidade interna.

\section{Introdução}

A demanda por uma maior flexibilidade nos anos 70 coincide com um período a partir do qual os mercados consumidores tornam-se cada vez mais instáveis e incertos (SAYER e WALKER, 1994), acentuando o padrão de competitividade exigido das empresas. Neste contexto, é fundamental o papel da microeletrônica e da tecnologia da informação, pois elas permitem uma produção mais diversificada e uma coordenação mais próxima das funções de fornecedores e produtores junto ao mercado. 
É ainda importante assinalar que, qualquer mudança tecnológica envolve uma profunda mudança no ambiente de trabalho. A experiência japonesa demonstra que, para o alcance da flexibilidade é importante, principalmente, um profundo conhecimento das práticas de trabalho e, antes de qualquer reestruturação tecnológica é necessário haver um levantamento dos problemas organizacionais. Para Sayer e Walker (1994), os chamados "novos tipos de produção" estão muito mais associados com a organização do trabalho do que com o hardware das novas tecnologias.

A flexibilidade também está ligada à formação das redes de empresas fornecedoras. Nestas redes interagem empresas com diferentes especialidades que, quando vistas em separado, apresentam um alto grau de rigidez e possuem limitações em termos de mercado e adaptação às mudanças. Porém, quando estas empresas estão integradas e em sinergia, têm capacidade de transformação permanente e, portanto, maior capacidade de adaptação, de inovação e flexibilidade.

Dentre as novas estratégias implementadas na indústria, em particular pelas montadoras automobilísticas, destacam-se a adoção dos novos sistemas produtivos em rede tais como o Condomínio Industrial e o Consórcio Modular. O Condomínio Industrial é a configuração produtiva na qual fornecedores de primeira linha (first tiers) de componentes ou subconjuntos localizam-se ao redor da montadora ou num raio relativamente pequeno da planta; em alguns casos, os fornecedores localizam-se em terrenos da própria fábrica. No Consorcio Modular, um pequeno número de fornecedores de primeira linha tornam-se responsáveis pela montagem dos produtos, cabendo à empresa as atividades de coordenação, logística, controle da qualidade, desenvolvimento de produtos, marketing e vendas (MARX, ZILBOVICIUS e SALERNO, 1997).

Outra forma de flexibilização está relacionada à revisão da legislação do trabalho, fenômeno ocorrido na Europa nos anos 80 e 90 (FINKEL, 1994) e atualmente em curso no Brasil. A necessidade de reformulação das leis do trabalho é freqüentemente justificada, sobretudo no caso da revisão da legislação brasileira, pela criação de formas alternativas de contratação, que se adaptem às oscilações econômicas e produtivas, permitindo uma maior competitividade. Esta medida de flexibilização está associada à legalização da subcontratação, terceirização e contratação por tempo limitado ou de trabalho parcial, e à eliminação dos custos de salário indiretos, como os de previdência e seguridade social.

Alguns autores (SALERNO, 1997; MARTIN, 2001) definem a flexibilidade como o resultado da interação dos fatores extra e intra empresa. Desta forma, a necessidade de flexibilidade está vinculada ao tipo de processo, de produto, de mercado, da estratégia competitiva, da organização e das relações de trabalho, ou seja, vai depender de todo o escopo de relações da firma e da gestão do trabalho. 
De acordo com o estudo desenvolvido por Martin (2001) em três montadoras do setor automobilístico no México, Estados Unidos e Brasil, é possível identificar um "imbricamento de flexibilidades". Para o autor, o setor automobilístico em todo o mundo tem sido o catalisador de uma série de transformações tecnológicas, econômicas e sociais e, também, onde se verifica uma maior incorporação das distintas variantes da flexibilidade. Estas variantes se traduzem pela adoção de plataformas comuns a dois ou mais veículos, o estabelecimento dos mecanismos de fornecimento globais (global e follow sourcing) e a utilização de técnicas de organização do trabalho da chamada produção enxuta ou produção flexível. Neste sentido, as possibilidades da flexibilidade do trabalho e da produção estão submetidas ao contexto das relações sociais e econômicas nas quais as firmas estão inseridas, suscitando, assim, uma enorme heterogeneidade no padrão de desenvolvimento verificado em cada planta.

O objetivo deste trabalho é analisar a flexibilidade no setor automobilístico brasileiro, com base no estudo de caso de três plantas automotivas ( VW de Resende/RJ, Peugeot-Citröen de Porto Real/RJ e Mercedes Benz de Juiz de Fora/MG) e propor um modelo de análise, a partir dos conceitos teóricos abordados, que é utilizado no estudo das três plantas.

A metodologia utilizada neste trabalho inclui pesquisa bibliográfica nacional e internacional e pesquisa de campo, realizada por meio de entrevistas com funcionários de diferentes níveis das empresas, com membros das Comissões de Fábrica e com diretores dos sindicatos locais, observação participante e análise dos documentos das empresas.

\section{Definição de um Modelo de Análise da Flexibilidade Externa e da Flexibilidade Interna no Setor Automobilístico Brasileiro}

No estudo desenvolvido neste trabalho, buscamos construir uma definição de flexibilidade que compreende duas dimensões correspondentes aos dois contextos (interno e externo à empresa) descritos anteriormente: flexibilidade interna e flexibilidade externa. Consideramos que os dois tipos de flexibilidade só podem ser considerados em toda a sua potencialidade e extensão como variáveis absolutamente sistêmicas, imbricadas e interdependentes, não sendo passíveis de análise isolada. Identificamos o entrelaçamento, ou imbricamento, de diversas possibilidades de flexibilidade que viabilizam a diminuição dos custos com o trabalho e com encargos para as empresas e um acréscimo da responsabilidade do trabalhador com os processos de produção, com as metas de produtividade e, em última instância, com a sua própria formação, tendo por objetivo aumentar a competitividade das empresas. 
A partir de diversos estudos desenvolvidos no setor automobilístico (ROLDAN e SEGRE, 2002; SEGRE, 2002; NASCIMENTO e SEGRE, 2002; NASCIMENTO, SEGRE e MARTINS, 2002; NASCIMENTO e SEGRE, 2003a; NASCIMENTO e SEGRE, 2003b; NASCIMENTO, 2004) identificamos os fatores fundamentais para a compreensão da flexibilidade interna e externa neste setor no Brasil. Desta forma, apresentamos na tabela 1 um modelo de análise que integra as variáveis específicas da flexibilidade externa e da flexibilidade interna.

Tabela 1 - Variáveis da Flexibilidade Externa e da Flexibilidade Interna na Indústria Automobilística Brasileira

\begin{tabular}{|c|c|}
\hline Flexibilidade Externa & Flexibilidade Interna \\
\hline Contexto das Relações de Trabalho & $\begin{array}{c}\text { Formas de Organização dos Sistemas } \\
\text { Produtivos }\end{array}$ \\
\hline Atuação Sindical & Formas de gestão do trabalho \\
\hline $\begin{array}{c}\text { Condições Fiscais para a Localização das } \\
\text { Plantas }\end{array}$ & Formas de Organização do Trabalho \\
\hline
\end{tabular}

Fonte: Elaborado pelas autoras

No que diz respeito aos fatores que propiciam a flexibilidade externa, em particular no setor automobilístico no Brasil, podemos apontar àqueles relacionados às mudanças nas relações de trabalho e nas relações industriais: a desregulamentação das leis trabalhistas, a diminuição e a fragmentação do poder dos sindicatos, que especialmente no setor automobilístico foi agravada com o fim da Câmara Setorial do Setor Automobilístico no início do governo FHC. Outros fatores a serem considerados são a difusão das práticas de subcontratação e terceirização, favorecidas pela adoção dos novos sistemas produtivos, como os Condomínios Industriais e os Consórcios Modulares, além dos incentivos concedidos às empresas para a sua localização nos Estados e municípios.

O outro tipo de flexibilidade, a flexibilidade interna, é aquela relacionada às transformações na própria organização do trabalho e da produção, à adoção de tecnologias mais flexíveis em consonância com o paradigma da produção enxuta e, como conseqüência, a definição de novas exigências sobre a mão-de-obra. Em particular no setor automobilístico brasileiro, a adoção das técnicas de trabalho em grupo, em conjunto com a polivalência, permite um uso da mão-de-obra mais flexível, no sentido em que possibilita uma redistribuição dos trabalhadores de acordo com as demandas produtivas da empresa, segundo a ótica da multifuncionalidade.

O potencial de flexibilidade possibilitado por estes elementos é ampliado, de forma evidente, por um contexto de crescente afrouxamento das relações legais de trabalho. Além deste fator, o 
aumento do desemprego também é decisivo para a flexibilidade, na medida em que cria um exército de reserva que é utilizado pelas empresas como moeda de barganha junto aos empregados, em situações de demissão, negociação salarial, jornada de trabalho etc, tal como veremos na seção seguinte.

\subsection{Desregulamentação do Trabalho, Enfraquecimento da Ação Sindical e Guerra Fiscal: a Flexibilidade Externa.}

O debate sobre a necessidade da mudança no sistema brasileiro de legislação do trabalho teve início na década de 80. Essa discussão, porém, só foi amadurecida ao longo da década de 90, assim como a implementação das mudanças efetivas na legislação.

A natureza dos objetivos da reforma trabalhista no Brasil é uma questão que têm suscitado profundo debate nos meios acadêmicos e sindicais, seja sobre o caráter positivo ou negativo da flexibilização para o trabalho, seja sobre a própria indefinição da categoria trabalho em si.

Grande parte das mudanças na legislação brasileira foi implementada no segundo semestre de 1998, no bojo da campanha presidencial para a reeleição, em consonância com as políticas recomendadas pelo Fundo Monetário Internacional para contenção do desemprego. Contudo, tais medidas visavam principalmente não a redução do desemprego, mas sim o estabelecimento de ajustes sobre o mercado de trabalho.

É interessante destacar aqui as conclusões do estudo realizado por Pochmann (2001) que mostram que apesar das políticas governamentais serem orientadas para a diminuição do desemprego, não houve um aumento da oferta de emprego no mercado de trabalho brasileiro neste período. Para o autor, a reforma da legislação, aliada às condições econômicas e do mercado de trabalho, contribuíram para acentuar a tendência à precarização das condições de trabalho já observadas desde o início da década de 90.

Também neste período foram realizadas mudanças na legislação sindical modificando as relações de trabalho, dentre as quais podemos identificar o fim da unicidade sindical e das contribuições compulsórias, assim como a revisão do poder normativo da justiça do trabalho. Elas pressupõem uma acentuação da flexibilidade do trabalho visto que instituem a descentralização das negociações coletivas e, conseqüentemente, contribuem para uma maior fragilidade do poder sindical, restringindo seus espaços de representação.

Além da mudança nas formas de regulação das relações de trabalho, as empresas que vieram instalar-se no país na última década, mais especificamente as empresas automotivas, foram beneficiadas com a verdadeira guerra que se instalou entre estados e municípios pela atração dos novos 
investimentos. A descentralização espacial do setor automotivo no Brasil está relacionada, desta forma, à intensa competição entre os locais que oferecem melhores condições físicas e tributárias para a instalação das fábricas. São apontados também como determinantes para a escolha das montadoras o custo da mão-de-obra, as vantagens específicas de cada localidade, o grau de combatividade do sindicato e a saturação espacial. Entretanto, como assinala Arbix (2000), a oferta de empregos gerada por estas empresas, no geral, fica muito aquém das promessas feitas antes da instalação.

Os fatores abordados nesta seção, referentes à flexibilidade externa, ao se integrarem aos aspectos da flexibilidade interna, propõem condições significativas de flexibilidade e competitividade para as empresas, tal como veremos nos estudos de caso. Na seção a seguir apresentamos os elementos associados à obtenção da flexibilidade interna.

\subsection{Novos Sistemas Produtivos, o Trabalho em Grupo e a Adoção do Modelo de Avaliação por Competências: a Flexibilidade Interna}

Nos últimos trinta anos as empresas do setor automobilístico brasileiro sofreram profundas transformações nos seus processos de organização e gestão do trabalho, sobretudo com a adoção das técnicas japonesas. Dentre estas técnicas, foram mais difundidas nas empresas do setor o trabalho em grupo e as ferramentas para a obtenção da qualidade total, além do emprego da polivalência e da multifuncionalidade.

Observa-se ainda, aliada a este processo, uma mudança na própria concepção da formação e da qualificação do trabalhador. Não basta ao trabalhador ter a qualificação técnica formal; ele deve ter também um conjunto de habilidades ou "competências" de relacionamento, tomada de decisão, articulação de idéias e utilização dos conhecimentos. Neste sentido, o funcionário passa a ser avaliado segundo um "modelo de competências", e sua evolução profissional, assim como a própria manutenção do seu emprego, dependem desta avaliação. A seguir pretendemos analisar de que forma estes elementos (o trabalho em grupo, a polivalência e o modelo de avaliação de competências) contribuem para a obtenção da flexibilidade interna na indústria automobilística brasileira.

No que diz respeito ao trabalho em grupo, no Brasil, verificamos a adoção maciça dos chamados Grupos Enriquecidos, conforme assinalado em diversos trabalhos (SALERNO, 1995; MARX, 1997; MARX, 1998). Os Grupos Enriquecidos, que podem ser entendidos como uma adaptação do trabalho em grupo japonês, têm por objetivo uma organização do trabalho menos taylorizada, com a participação dos trabalhadores em aspectos relativos à melhoria da qualidade dos processos e dos produtos, à resolução dos problemas decorrentes da execução das atividades e do 
processo de trabalho, à distribuição de tarefas e atribuições aos membros do grupo. A autonomia destes grupos, contudo, é bastante restrita e eles reproduzem o sistema hierárquico clássico taylorista, mantendo uma nítida separação entre planejamento e execução. O trabalho em grupo permite também uma maior flexibilidade, na medida em que pressupõe o uso de várias habilidades técnicas e comportamentais do trabalhador.

Deve-se ressaltar ainda que, nas empresas brasileiras, a polivalência e a multifuncionalidade estão longe de representar um aumento da qualificação do trabalhador por meio da execução de múltiplas tarefas de maior nível de complexidade. Abramo (1990, apud SOUZA, SANTANA e DELUIZ, 2002) define a polivalência no Brasil como um acúmulo de tarefas simplificadas e com pouquíssimas exigências de qualificação, que não contém um enriquecimento do trabalho, guardando ainda resquícios de um padrão de gestão do trabalho taylorizado.

O que se percebe é que as empresas optam pela flexibilização via mudança organizacional, em detrimento da incorporação de mudanças tecnológicas. Vários estudos realizados nas indústrias automobilísticas demonstram que, em particular no Brasil, a utilização de técnicas de organização do trabalho, em conjunto com a terceirização, têm um potencial de flexibilidade muito grande. Some-se a isto o custo do investimento em equipamentos de base microeletrônica, que é muito mais elevado do que os custos de implantação das inovações organizacionais (NASCIMENTO e SEGRE, 2002; NASCIMENTO, SEGRE e MARTINS, 2003). Esta perspectiva é reforçada pelas conclusões do estudo desenvolvido por Fleury (1995, apud SOUZA, SANTANA e DELUIZ, 2002), realizado em empresas líderes de diferentes setores. Segundo este estudo, as estratégias adotadas por estas empresas para aumentar sua competitividade são: redução de custos por meio da terceirização de atividades de suporte e focalização no core business da empresa, adoção de inovações organizacionais como o Just in Time e as ferramentas de Controle de Qualidade Total (TQC), utilização de mão-de-obra polivalente e o enxugamento de pessoal (downsizing). Como se pode verificar, estas iniciativas de racionalização, que levam também a uma maior flexibilidade produtiva, não incluem a mudança tecnológica.

Já no que tange ao modelo de competências, a adoção deste modelo sinaliza para uma situação paradoxal. Por um lado, este processo pode ser visto pela valorização do trabalho, através do seu caráter mais intelectualizado, menos prescrito, demandando a utilização de competências que envolvem domínios cognitivos mais complexos (ZARIFIAN, 2001). Por outro lado, verifica-se nas empresas brasileiras a intensificação do trabalho e a desprofissionalização, que são produtos de uma polivalência "espúria" (DELUIZ, 2001), conseqüência do reagrupamento de tarefas e subtração dos postos de trabalho, resultante de um uso da força de trabalho voltado unicamente para a obtenção de maior flexibilidade e de ganhos de produtividade. Verificamos, assim, a contradição existente entre o discurso 
da valorização da mão-de-obra e a implementação do modelo que beneficia principalmente as empresas.

\section{Estudos de Caso}

A seguir verificamos como estas diferentes esferas da flexibilidade se apresentam em três empresas do setor automobilístico brasileiro, com base nos estudos de caso realizados nas plantas da Volkswagen em Resende/RJ, da Mercedes Benz de Juiz de Fora/MG e da Peugeot Citröen de Porto $\mathrm{Real} / \mathrm{RJ}$.

\section{1. O Caso do Consórcio Modular da Volkswagen Resende/RJ}

A fábrica de caminhões e ônibus da Volkswagen (VW) em Resende/RJ iniciou suas operações em 1996, sendo a primeira planta no mundo concebida dentro do novo conceito de produção denominado Consórcio Modular. A fábrica de Resende é a única fábrica de caminhões da VW no mundo.

De acordo com os pontos levantados com os entrevistados na pesquisa de campo e nos estudos desenvolvidos por Ramalho e Santana (2002) e Rocha (2003), foram citados os seguintes critérios de escolha do município de Resende como o local para construção da nova fábrica: a localização geográfica do município; a participação, em termos de investimentos e incentivos fiscais dos governos do estado e do município; a oferta de mão-de-obra qualificada; o baixo nível de emprego na região, que permite a prática de baixos salários e a existência de um sindicato que, apesar de ser um dos mais tradicionais do setor, não tinha nenhuma experiência no setor automotivo e não tinha nenhuma base formada no município de Resende.

A fábrica é formada de oito módulos (fornecedores), instalados na própria planta, cada um responsável por uma seqüência de montagem dos veículos. A VW é responsável, na prática, pela verificação da qualidade do carro e pela coordenação das atividades dos outros sete módulos de montagem, além do projeto dos veículos e do processo de vendas. O total de funcionários da fábrica era de 2100 pessoas em 2004, incluindo neste número os trabalhadores terceiros (500 pessoas, nas atividades de manutenção, logística, bombeiro, restaurante, ambulatório, segurança e limpeza) e os funcionários dos módulos.

Como observa Bresciani (2001), o consórcio é formado por algumas empresas fornecedoras da 
VW em outras plantas e já tradicionalmente estabelecidas em seus negócios. Tal fato não impede, entretanto, que estejam submetidas a um acordo de produção por vezes desfavorável. O controle da VW sobre os consorciados se dá, sobretudo, nos itens de qualidade. Observe-se que o custo das perdas é arcado pelos módulos. Ainda que o defeito tenha sido originado em apenas um deles, todos os módulos são penalizados.

No início das atividades, a produção da planta estava em torno de 75 veículos/dia e em 2004 a produção era de 112 veículos por dia, em um único turno. É importante assinalar que a produção da fábrica atinge picos de 128 caminhões produzidos por dia, em um único turno. Dentre as novas plantas construídas no país no período da nova migração, a da VW Resende é a que tem obtido um melhor desempenho em termos de mercado e faturamento.

As contratações para a empresa e para os módulos foram realizadas tendo por base o atendimento à exigência de $2^{\circ}$ grau completo ou experiência no setor metalúrgico ou siderúrgico. A VW utilizou o SENAI como veículo de contratação (foram privilegiados ex-alunos dos cursos técnicoprofissionalizantes) e também como centro de treinamento dos futuros funcionários da empresa, sobretudo no sistema de trabalho em equipe e nos conceitos do consórcio modular, que demandam uma filosofia de trabalho totalmente diferente e inovadora.

A ênfase nas competências "não formalizadas" para o trabalho (ou que não são adquiridas na escola ou na formação técnica) é essencial para a adaptação do trabalhador na produção da VW. O sistema de produção, por suas próprias características, demanda trabalhadores polivalentes (cabe lembrar que são montados 30 modelos distintos, entre caminhões e ônibus, na mesma linha) e com um envolvimento e comprometimento maior na produção e, sobretudo, com a qualidade, uma vez que eles produzem um produto de outra empresa que não aquela ao qual estão vinculados. Para isso, são realizados treinamentos periódicos com os funcionários, pelos módulos, no próprio local de trabalho. É possível identificar uma ampla utilização da flexibilidade interna, que é determinada pela organização do trabalho em grupo e pela multifuncionalidade dos funcionários, favorecida pela organização da produção no Consórcio Modular.

A avaliação de desempenho do funcionário, que não é reconhecida pela empresa como uma avaliação por competências, é de responsabilidade do supervisor de cada área. Segundo os membros da Comissão de Fábrica, esta avaliação é feita anualmente e tem por objetivo fornecer subsídios para a melhoria da produtividade do trabalhador. Os requisitos avaliados são o desempenho na atividade, a disciplina e o cumprimento dos horários.

Embora enfatizada a importância do comprometimento dos funcionários com o processo produtivo, o envolvimento dos trabalhadores na planta se dá, ainda, de forma muito restrita e em 
espaços delimitados pela própria gerência e neste sentido, como apontam diversos autores, a planta de Resende segue um modelo de organização do trabalho em equipes conservador, sem maiores ganhos de autonomia e participação para os trabalhadores (BRESCIANI, 2001; ROCHA, 2002).

Em termos de inovação, a experiência de Resende se restringe à implantação do Consórcio Modular. Tal como afirma Bresciani (2001), a adoção desse sistema possibilita uma ampla flexibilidade, que se traduz para a empresa, pela capacidade de produzir diferentes modelos. No que tange às inovações tecnológicas, a planta segue um modelo tradicional, com a maioria das atividades manufaturadas, sendo apenas semi-automatizada na área de pintura.

\subsection{O Caso da Mercedes Benz de Juiz de Fora}

O início das atividades da fábrica da Mercedes Benz em Juiz de Fora - MG ocorreu em 1999. A fábrica pertence ao grupo Daimler-Chrysler e sua entrada no Brasil estava associada à estratégia mundial do grupo de expansão para os mercados emergentes, com a produção de veículos de passeio, como forma de aumentar sua competitividade. A fábrica de Juiz de Fora é a primeira voltada para a produção de automóveis da marca Mercedes Benz para o mercado nacional. A fábrica emprega cerca de 1021 trabalhadores diretos e indiretos. Deste total, cerca de $85 \%$ estão envolvidos com as atividades de operação. A fábrica terceiriza apenas os trabalhadores envolvidos com limpeza e alimentação.

Segundo as pessoas entrevistadas, tanto da empresa quanto do sindicato, os fatores determinantes para a construção da planta em Juiz de Fora foram: a localização do município, próximo de uma rodovia de fácil trânsito para os estados de São Paulo, Minas Gerais e Rio de Janeiro, além da proximidade dos portos do Rio de Janeiro, Sepetiba e Santos; a existência de mão de obra local qualificada sem oportunidades de emprego na região, em razão da decadência de várias indústrias; a possibilidade de oferta de baixos salários em função da baixa competitividade local em termos de volume de postos de trabalho e o padrão de atuação do sindicato, mais receptivo ao diálogo e com atuação menos reivindicativa do que o Sindicato dos Metalúrgicos do ABC, em São Paulo.

No início a fábrica estava voltada para a produção somente do modelo Classe A, com capacidade produtiva de 70.000 veículos/ano. Entretanto, desde a sua inauguração, parte significativa desta capacidade ficou ociosa. A baixa produção, deu-se principalmente em função das mudanças cambiais ocorridas na economia brasileira no início do ano de 1999. Considerando-se que cerca de $38 \%$ do veículo é composto por peças importadas seu preço final para o consumidor fícou acima do planejado pela montadora provocando uma demanda menor à esperada. A produção deste modelo tem previsão de término na segunda metade de 2005. Para utilizar a capacidade excedente, a fábrica 
começou a montar também o modelo Classe C em 2001. Este modelo é produzido em $\mathrm{CKD}^{1}$ para ser exportado para os Estados Unidos.

Em função do alto índice de ociosidade da planta e devido ao compromisso de permanecer 10 anos no Brasil, estão sendo cogitadas algumas alternativas para a sua sobrevivência, entretanto até o momento nenhum novo projeto foi confirmado para a fábrica de Juiz de Fora.

A planta foi projetada para adotar um modelo de produção similar ao Condomínio Industrial, o qual é denominado freqüentemente pelos engenheiros da planta como uma "modularização de fornecedores". Cerca de dez fornecedores, os de primeira linha, estão localizados na planta, entregando módulos já prontos ou componentes numa gestão da produção baseada nos princípios do Just in Time. Contudo, na linha de produção a MBB não tem funcionários de terceiros operando.

De acordo com os funcionários entrevistados, a planta é caracterizada por um baixo nível de automação. A título de comparação podemos considerar a planta de Rastaad, na Alemanha, a qual é modelo para Juiz de Fora: a montagem bruta alemã é 100\% automatizada, enquanto que no Brasil o nível de automação é de 30\%. Segundo os engenheiros da empresa entrevistados, a razão crucial para a baixa automatização da fábrica é o custo da mão de obra e a baixa produção. A estratégia tecnológica da MBB-JF está voltada para a automação nos pontos que exigem ergonomia e em situações que demandam uma repetibilidade com qualidade muito grande, ou com acesso bastante dificultado. No que diz respeito à organização do trabalho, a Mercedes-Benz Juiz de Fora está voltada para assegurar a flexibilidade do processo por meio da utilização da multifuncionalidade e rotação de tarefas, com a adoção do trabalho em grupo.

A produção na fábrica da MBB-JF está submetida a um conjunto de ferramentas e procedimentos padronizados denominado Sistema de Produção Mercedes Benz Juiz de Fora (SPJ). Todos os funcionários da produção são treinados na incorporação dos princípios de produção do SPJ e em suas respectivas ferramentas, sendo cada funcionário responsável pelo uso destas ferramentas em sua área de trabalho. A gerência enfatiza fortemente a preocupação com a segurança e a qualidade total: todos os trabalhadores entrevistados parecem ter absorvido totalmente o princípio de fazer certo da primeira vez. As ferramentas englobam aspectos técnicos da produção, sobretudo os elementos comportamentais necessários para o processo de trabalho.

A qualidade dos veículos Classe A produzidos em Juiz de Fora é considerada a melhor do mundo, de acordo com os parâmetros da Mercedes Benz. Este padrão de qualidade, segundo muitos entrevistados, está associado à baixa produção e também ao esforço dos funcionários da planta de Juiz

\footnotetext{
${ }^{1}$ CKD: Completely Knocked Down - todas as peças ou componentes que compõem a montagem do veículo são importados em kits completos.
} 
de Fora para mostrar ao grupo Daimler Chrysler que ainda vale a pena direcionar projetos para esta planta, para mantê-la em operações.

O sistema de avaliação de desempenho da fábrica foge do modelo tradicional, utilizando a análise por competências e habilidades, ainda em fase de implantação para o pessoal operativo. Este modelo está em fase de testes e foi desenvolvido tomando por base as especificidades da planta de Juiz de Fora, segundo a cultura local, não estando baseado no modelo alemão. Utiliza-se uma metodologia de avaliação pelo sistema $360^{\circ}$, onde todos os envolvidos no processo de trabalho se avaliam uns aos outros. Esta avaliação ocorre uma vez por ano. O modelo de avaliação é utilizado para promoção de funcionários e para a definição de salários.

Com relação à política salarial da empresa, uma reclamação constante dos trabalhadores entrevistados diz respeito à falta de critérios explícitos para definir a progressão das faixas salariais. Os trabalhadores fazem uma crítica indireta ao modelo de avaliação de desempenho, ao qual a remuneração está atrelada, por não entenderem os critérios de aplicação da avaliação. Para o nível operacional, a avaliação em $360^{\circ}$ é fechada em conjunto pelo funcionário e o líder, e é referendada pelo supervisor. Contudo, muitas vezes o funcionário se sente pressionado a acatar a avaliação do líder, sem ter espaço para questionamentos da avaliação. Para os operadores, este sistema de avaliação torna o processo muito personalizado, e faz com que ocorram distorções nas avaliações e privilégios para os funcionários que estão mais próximos dos líderes. Eles também consideram a política salarial injusta por que permite que operadores que têm a mesma função recebam salários distintos.

Como podemos perceber, desde o processo de instalação da fábrica os elementos da flexibilidade externa e interna estão presentes. No que tange à flexibilidade externa, destacam-se os critérios que determinaram a escolha do município de Juiz de Fora para a construção da planta e os benefícios concedidos à montadora, cada vez maiores, para que Juiz de Fora "ganhasse" a concorrência com os outros municípios. A barganha estabelecida entre a montadora e os municípios proporcionou condições ótimas de entrada da planta na região, além do aproveitamento de diversos aspectos da flexibilidade externa (como por exemplo, os baixos salários da região, a boa qualificação da mão de obra e a ação do sindicato local) . Por outro lado, ainda no que diz respeito aos salários, a empresa consegue ampliar ainda mais seu potencial de flexibilidade ao praticar salários diferenciados para funcionários de uma mesma função. Este fato caracteriza uma situação onde a flexibilidade externa potencializa fortemente a flexibilidade interna, pois os funcionários submetem-se à esta distinção salarial por estarem imersos em um contexto local (e nacional) de baixos salários e crise do emprego. 


\subsection{O Caso da Peugeot-Citröen em Porto Real/RJ}

A produção da fábrica da Peugeot-Citröen (Centro de Produção de Porto Real - CPPR) teve início em agosto de 2001. A fábrica emprega 1348 trabalhadores e destes, cerca de 500 têm contrato de trabalho temporário ou são terceirizados nas áreas de manutenção, limpeza, segurança e alimentação.

A fusão da Peugeot com a Citröen data da década de 70, entre 1973/74, constituindo assim o grupo PSA. É importante remarcar que a filosofia de organização da PSA é, segundo o Diretor de Recursos Humanos da empresa: "Um grupo, duas marcas". Nos últimos anos, o grupo passou da nona posição entre os maiores fabricantes mundiais de veículos, para a sexta posição. Um dos fatores apontados pelo Grupo PSA para essa evolução está relacionado diretamente ao compartilhamento de plataformas de produção. Atualmente, são utilizadas apenas três plataformas para a produção de todos os modelos de carros das marcas Peugeot e Citröen no mundo. As marcas são totalmente independentes, com rede comercial, marketing e política comercial distintas, geridas por direções independentes. A estratégia do grupo, no entanto, é comum para as duas marcas. Este fator está relacionado à estratégia de crescimento adotada pela PSA nos últimos anos, a qual está centrada na expansão em direção aos mercados emergentes e entre estes mercados, o Mercosul. Esta estratégia se justifica pela saturação do mercado de automóveis europeu e pela pouca penetração da PSA nos mercados norte-americano e japonês. Neste sentido, o Brasil foi escolhido como pólo de produção do Mercosul, por ser um mercado em franco crescimento.

A escolha pela localização da empresa no município de Porto Real foi resultado da análise das condições de vários estados brasileiros. As razões apontadas pelos diversos interlocutores para a localização da planta no município foram: a significativa participação do governo do Estado do Rio de Janeiro no processo, entrando como parceiro da PSA com $32 \%$ das ações de todo investimento (o valor do investimento total na construção da fábrica foi de US\$ 600 milhões); a proximidade dos centros fornecedores; a qualificação da mão de obra local, considerada satisfatória, aliada à diminuição dos índices de emprego observada nos últimos vinte anos na região e a atuação do sindicato, destacando-se o fato do Sindicato local pertencer à Força Sindical, central sindical considerada mais maleável, segundo definição do dirigente sindical entrevistado.

O projeto da fábrica se assemelha a um Condomínio Industrial, no qual os fornecedores de primeira linha vieram junto com a PSA. Na região onde está localizada encontram-se seis fornecedores que formam um tecnopólo e produzem não apenas para o CPPR, mas também para outras empresas locais. Não obstante, o nível de integração com fornecedores nacionais é ainda muito pequeno, o que 
faz com que quase $60 \%$ das peças utilizadas na produção sejam importadas, aumentando consideravelmente o preço final do veículo.

A capacidade de produção do CPPR é de 100 mil veículos/ano com três equipes (turnos) de produção. Entretanto a fábrica opera com duas equipes, com jornadas de 42 horas semanais, na fabricação de três modelos de automóveis em duas plataformas: o Citröen Xsara Picasso, o Peugeot 206 e o Citröen C3, além da fabricação de motores do modelo 206 para exportação. O número de veículos produzidos no ano de 2004 foi 48 mil. Para 2005, o CPPR espera aumentar esta produção para 64 mil veículos, com a introdução de mais dois novos modelos na montagem.

Segundo os funcionários entrevistados, a planta da PSA em Porto Real foi projetada segundo um conceito inovador e pioneiro para o grupo no mundo: é a primeira fábrica a produzir as duas marcas em uma mesma linha. Além disso, ela foi criada com base na idéia de se buscar produzir o máximo possível de forma enxuta: com o menor número de trabalhadores possível obtendo o máximo de produtividade, com menores custos e recursos disponíveis.

Identificamos que a estratégia de compartilhamento de plataformas, implementada pela empresa, atende ao objetivo da montadora de manter uma fábrica "enxuta" como relatamos anteriormente, permitindo maior competitividade e ainda uma significativa flexibilidade da produção. Deve se considerar ainda, que para possibilitar esta estrutura enxuta, a fábrica necessariamente conta com uma enorme flexibilidade interna, implementada através de uma organização do trabalho em grupos multifuncionais, capacitados para executar uma grande variedade de operações nos diferentes modelos produzidos numa mesma linha.

O trabalho na planta da Peugeot-Citröen em Porto Real é organizado em equipes multifuncionais. As áreas de produção são formadas por 5 ou 6 equipes, lideradas por um RUEP (Responsável pela Unidade Estratégica de Produção). O RUEP também é denominado pelos funcionários como "funcionário multifuncional", pois ele é responsável por ocupar postos de trabalho quando um trabalhador estiver ausente, o que garante uma certa flexibilidade ao processo. No entanto, podemos identificar o emprego da multifuncionalidade em todos os funcionários da montagem e não apenas nos RUEPs pois, segundo os técnicos em recursos humanos entrevistados, com a adoção do trabalho em equipe o rodízio de funções é utilizado entre todos os participantes de cada equipe. Nas reuniões realizadas com os grupos, o RUEP deve arbitrar somente sobre os aspectos relativos ao processo de produção.

No que diz respeito ao nível de automação da planta, ele pode ser considerado pequeno. Segundo o Diretor de Recursos Humanos, o baixo índice de automação da planta brasileira foi uma escolha feita pela PSA em função das características locais, mais especificamente em função do baixo 
custo da mão-de-obra, e também por ser possível produzir veículos de alta qualidade no país com "pouco investimento em automação", como definiu o próprio entrevistado. Desta forma, a estratégia de automação da fábrica de Porto Real foi descrita como uma "busca pelo equilíbrio entre automação, qualidade e geração de empregos", evidenciando claramente que a flexibilidade externa propiciada pelas condições de emprego no Brasil determinaram o baixo índice de automação da planta. Para o Gerente de Metrologia entrevistado, a baixa automação também está intrinsecamente ligada ao volume de produção, ainda muito abaixo da capacidade da fábrica, além do custo da mão-de-obra.

A política de treinamento da empresa abrange tanto a formação técnica quanto a formação comportamental. Os objetivos do treinamento comportamental estão voltados para o maior comprometimento com a qualidade, com a resolução de problemas, com a segurança no trabalho e com a aquisição de competências necessárias para o trabalho em equipe. Segundo as entrevistas realizadas com os técnicos de recursos humanos da empresa, para conseguir executar as atividades com a qualidade exigida pela produção e com a diversidade de operações que eles devem incorporar para realizar seu trabalho, os funcionários da montagem devem ter uma visão global do processo produtivo, conhecendo as funções desempenhadas em cada área da produção. Neste sentido, é evidente que o nível de formação de $2^{\circ}$ grau dos operadores possibilita uma melhor compreensão das etapas do processo de produção, facilitando a incorporação da gama de operações presentes neste processo, possibilitando uma maior multifuncionalidade e, em última análise, maior flexibilidade.

Segundo o Diretor Sindical entrevistado, o salário pago na região de Resende e Porto Real é o menor de todo o setor automobilístico brasileiro. Para ele, este é indubitavelmente um fator de atração das empresas PSA e Volkswagen para aquela região. Este fato é ainda mais grave para os trabalhadores quando se consideram as perdas reais nos salários da PSA, que nos últimos três anos têm sido reajustados em um percentual abaixo do Índice Nacional de Preços ao Consumidor (INPC) e da inflação. As perdas verificadas na PSA são decorrentes das condições mais gerais de emprego e salários, desfavoráveis ao trabalhador e que enfraquecem as possibilidades de barganha do sindicato nas negociações com a empresa. Esta situação configura o que Pochmann e Moretto (2002) definem como Flexibilidade de Salários, e que identificamos como uma das variáveis que compõem a flexibilidade externa. Dentre as variáveis da flexibilidade externa presentes na PSA, encontramos ainda as condições oferecidas pelo governo do município e pelo governo do Estado para a implantação da empresa no local e a presença de uma representação sindical considerada "flexível" e apta à negociação pela empresa.

No que tange às variáveis da flexibilidade interna, estão presentes na organização do trabalho da PSA elementos marcadamente "flexíveis": o uso do trabalho em grupo; o uso de formas de gestão dos 
recursos humanos que não valorizam o saber e as competências adquiridas do trabalhador, pois não emprega estímulos à progressão na carreira, não contempla um Plano de Cargos e Salários e com políticas de remuneração claramente precarizantes para o trabalho.

\section{Conclusões}

Face à confrontação do referencial teórico com os estudos de caso analisados, podemos destacar como a contribuição mais relevante deste trabalho a identificação e a análise dos fatores externos e internos da flexibilidade nas empresas do setor automobilístico, assim como o papel desempenhado por estes fatores na constituição das firmas e na sua inserção no país. Conforme verificamos no levantamento bibliográfico, não existem estudos que abordem a flexibilidade sob a ótica do imbricamento de diversos fatores, especificamente no que diz respeito à inserção das firmas automobilísticas no Brasil na década de 90. Tal análise é fundamental visto que é o conjunto destas variáveis que determina a escolha do Brasil, pelas montadoras, como país receptor de investimentos e de novas plantas automotivas. Mostramos assim que, tanto nos fatores externos quanto nos internos, o Brasil oferece condições ótimas para o desenvolvimento da flexibilidade.

No que diz respeito à flexibilidade externa, destaca-se o papel dos fatores de localização, sobretudo da concorrência entre Estados e municípios em torno da concessão de incentivos fiscais e de infra-estrutura para atração das indústrias automotivas. A intensa guerra fiscal entre os governos assegurou para as empresas estudadas condições ótimas em termos de flexibilidade de negociação com os municípios dos acordos de instalação e operação das plantas. Observe-se que a oferta de investimentos e incentivos fiscais por parte dos governos dos municípios deu-se em troca de um número pouco significativo de empregos gerados. Tal fato confirma as conclusões apontadas por Ramalho e Santana (2002) acerca da finalidade destes incentivos governamentais, qual seja, o uso meramente político, com vistas às campanhas eleitorais estaduais e municipais. Estas condições favorecem sobretudo uma competitividade maior das plantas instaladas no Brasil em comparação com as de países que possuem uma legislação mais rígida, sindicatos mais fortes e relações de trabalho menos precarizadas.

A escolha realizada pelas montadoras foi por regiões com pouca ação sindical (greenfields). Nos casos da VW e da PSA, por exemplo, tal escolha baseou-se claramente em uma comparação com regiões com representação sindical de caráter mais combativo, sobretudo naquelas onde o sindicato é dirigido pela Central Única dos Trabalhadores. Neste sentido, os municípios de Resende e Porto Real, 
que são atendidos pelo mesmo sindicato, foram escolhidos por ter uma base metalúrgica liderada pela Força Sindical, o que significa para as empresas a possibilidade de um interlocutor mais submisso às suas pressões e uma maior flexibilidade nas negociações. No caso da MBB-JF, o município escolhido possui um sindicato dos metalúrgicos que, embora esteja vinculado à Central Única dos Trabalhadores, não tem tradição de negociação com o setor automobilístico.

Verificamos ainda que os baixos salários praticados no Brasil constituem um fator essencial para a definição das estratégias de localização e automação das empresas do setor. No contexto brasileiro de flexibilidade de contratação e de salários, torna-se mais competitivo para as empresas contratar mão-de-obra a baixo custo do que investir em tecnologia.

Nos três casos, ficou evidente o imbricamento das variáveis da flexibilidade interna. A flexibilidade possibilitada pelo tipo de sistema produtivo adotado, tanto o Consórcio Modular quanto o Condomínio Industrial, por meio da terceirização de módulos ou subconjuntos dos veículos, proporcionou às montadoras o máximo de flexibilidade produtiva e de custos. Além disto, destaca-se a flexibilidade da organização do trabalho, com o uso do trabalho em grupo, porém de forma distinta daquela verificada no modelo japonês de organização, engendrando condições de trabalho e relações industriais absolutamente distintas daquelas propaladas por este modelo. Concluímos, assim, que as empresas adaptam, ou hibridizam as técnicas do trabalho em grupo de acordo com suas necessidades específicas. Desta forma, o trabalho em grupo nestas empresas se traduz principalmente pelo uso da multifuncionalidade, a qual não representa nenhum acréscimo de conhecimento ao trabalhador, nem tampouco implica no seu crescimento profissional. A adoção da multifuncionalidade pressupõe somente o exercício de tarefas simples, e que na maioria das vezes induz à memorização de uma enorme variedade de operações, assegurando o máximo de flexibilidade e competitividade para as empresas. Além disso, o escopo de participação e reivindicação do trabalhador se restringe aos aspectos próprios do processo de trabalho; a multifuncionalidade, assim como o trabalho de reflexão sobre a tarefa e propostas de melhoria, a verificação de qualidade, a execução de pequenas manutenções e tomadas de decisões rápidas (algumas das competências exigidas aos trabalhadores) não são explicitamente remuneradas pelas empresas. Estas funções estão incorporadas às atividades cotidianas. O trabalho em grupo nestas empresas parece ser uma continuação do método fordista de execução do trabalho, adicionando-se a ele, contudo, um elenco de maiores responsabilidades para o trabalhador.

É ainda interessante destacar que, a partir das conclusões suscitadas por esta pesquisa, verificamos que a flexibilidade está revestida unicamente de aspectos negativos para o trabalho e para o trabalhador.

No que se refere ao contexto mais geral, podemos concluir que, apesar do Brasil constituir um 
"laboratório de experiências" produtivas (com a implantação de sistemas produtivos inéditos, como o Consórcio Modular), nenhum modelo, salvo exceções como o PQ-24 da VW, é projetado no país. Os projetos de veículos e os modelos de produção, assim como as estratégias de recursos humanos, marketing e de produção de algumas firmas permanecem sendo elaboradas nos seus países de origem. Este fato reforça a noção, há muito consolidada, de que o Brasil é um mero fornecedor de mercado consumidor e de mão-de-obra barata. Estas conseqüências para o país constituem, indubitavelmente, o resultado das estratégias globais das firmas e do papel destinado a ele no cenário global. Enfim, o tipo de flexibilização implementada pelas empresas contribui, de forma significativa, para a precarização das condições de trabalho e para o aprofundamento da dependência tecnológica e econômica do Brasil em relação aos países centrais.

\begin{abstract}
Through the case studies of three different Brazilian automotive plants, this work aims to analyze the flexibility of the Brazilian automotive sector. These studies led us to conclude that, in Brazil, flexibility depends more on organizational factors than on technological ones. We present a model of analysis focusing on the flexibility variables present in the Brazilian automotive companies. These variables have been classified into two different categories: the internal and the external ones. The case studies of the three companies, according to the proposed model, show that the Brazilian context offers excellent conditions for the implantation of assembling plants, which achieve flexibility without incurring on the legal obligation of investing on technology and/or on the diffusion of knowledge. Our methodology includes national and international bibliographical research, a field research approach utilizing employee's interviews, participant observation, and the analysis of documents belonging to the companies involved.
\end{abstract}

Key Words: brazilian automotive sector, flexibility, work relations, external flexibility, internal flexibility.

\title{
Referências
}

ARBIX, G. Guerra Fiscal e competição intermunicipal por novos investimentos no setor automotivo brasileiro. Dados, vol.43, nº1, Rio de Janeiro, 2000. Disponível em http://www.scielo.com.br.

BRESCIANI, L.P. Labour and Innovation in the Brazilian Truck Industry: The Case of MBB São Bernardo and VW-C Resende. Actes du GERPISA, n³0, França, 2001. Disponível em www.gerpisa.univ-evry.fr.

DELUIZ, Neise. O modelo das competências profissionais no mundo do trabalho e na educação: implicações para o currículo. Boletim Técnico do SENAC, v. 27, n³, Rio de Janeiro, 2001.

FINKEL, L. La Organización Social del Trabajo. Madrid: Ed. Pirâmide, 1994.

MARTIN, S. Globalização e Imbricamento da Flexibilidade do Trabalho: perspectivas contemporâneas da indústria automobilística nas Américas (Brasil, México e Estados Unidos). ABREU, Alice R. de P. (org.), Produção flexível e novas institucionalidades na América Latina. Rio de Janeiro: Ed. UFRJ, 2002. 
MARX, R.; ZILBOVICIUS, M. \& SALERNO, M.S. The 'Modular Consortium' in a new VW truck plant in Brazil: new forms of assembler and suppliers relationship. Integrated and Manufacturing Systems, V. 8, nº5, Montreal, 1997.

MARX, R. Trabalho em grupo, polivalência e controle. ARBIX, G. e ZILBOVICIUS, M., (orgs), De Jk a FHC: a reinvenção dos carros. São Paulo: Ed. Scritta, 1997.

MARX, R. Trabalho em Grupo e Autonomia como Instrumento de Competição. São Paulo: Ed. Atlas, 1998.

NASCIMENTO, R. P. e SEGRE, L. Flexibilidade das Relações de Trabalho e Flexibilidade Produtiva: uma análise da nova migração do setor automobilístico brasileiro. In: Anais da XXV Encontro Anual da ANPOCS, Caxambu, Minas Gerais, 2002.

NASCIMENTO, R.P.; SEGRE, L.\& MARTINS, M.A. Gestão de Recursos Humanos, o Modelo de Competências e a Construção da Flexibilidade: Estudo de Caso no Setor Automobilístico Brasileiro. ADM MADE, Ano 2, n², Julho/Dezembro, 2002.

NASCIMENTO, R. P. e SEGRE, L. Relações de Trabalho em um Contexto Flexível: uma análise em duas empresas do setor automobilístico brasileiro. In. ENCONTRO DA ASSOCIAÇÃO LATINOAMERICANA DE SOCIOLOGIA DO TRABALHO, 3, 2003, Havana. Anais... , Havana: ALAST, 2003a.

NASCIMENTO, R. P. e SEGRE, L. Flexibilidade Produtiva e o Modelo de Competências: estudo de caso no setor automobilístico brasileiro. In. ENCONTRO NACIONAL DE ENGENHARIA DE PRODUÇÃO, 23., 2003, Ouro Preto. Anais... Porto Alegre: ABEPRO, 2003b.

NASCIMENTO, R.P. Flexibilidade Externa versus Flexibilidade Interna: uma análise das variáveis da flexibilidade na indústria automobilística brasileira. Tese de Doutorado. Programa de Engenharia de Produção, COPPE/UFRJ, 2004,

POCHMANN, M. A década dos mitos. Rio de Janeiro: Ed. Contexto, 2001.

POCHMANN, M e MORETTO, A. Reforma Trabalhista: A Experiência Internacional e o Caso Brasileiro. Cadernos Adenauer, Ano III, n², Julho, 2002.

RAMALHO, J. R. e SANTANA, M. A. A Indústria Automobilística no Rio de Janeiro: relações de trabalho em um contexto de desenvolvimento regional. NABUCO, Ma. R.; NEVES, M. de A. e NETO, A.M. de C., Indústria Automotiva: a nova geografia do setor produtivo. Rio de Janeiro: DP\&A Editora, 2002.

ROLDAN, O.F.M. e SEGRE, L. Internacionalização da Indústria Automobilística: Estudo de Caso da Renault França/Colômbia/Brasil em relação à adoção do trabalho em grupo. In ENCONTRO NACIONAL DE ENGENHARIA DE PRODUÇÃO, 22., Curitiba, 2002. Anais... Porto Alegre: ABEPRO, 2002.

ROCHA, L. de M. O Novo Discurso da Qualificação Profissional e os Trabalhadores do 'Consórcio Modular' em Resende/RJ. Trabalhadores, Sindicatos e a nova Questão Social, Seminário Intermediário, GT ANPOCS, Universidade de São Paulo, São Paulo, 2003. Disponível em http://www.sindicalismo.bridge.com.br.

SALERNO, M. S. Flexibilidade e Organização Produtiva: elementos para transformar o termo flexibilidade numa categoria analítica; elementos para análise da produção na indústria. CASTRO, N.A., A Máquina e o Equilibrista. Rio de Janeiro: Editora Paz e Terra, 1995.

SAYER, A. e WALKER, R. La Nueva Economia Social. Espanha: Ministerio del Trabajo y Seguridad Social, 1994. SEGRE, L. (coord). Modernização Tecnológica e Impactos Socio-Econômicos. Relatório Final do Projeto de Pesquisa Finep, Rio de Janeiro, 2002.

SOUZA, D. B de; SANTANA, M. A. e DELUIZ, N. Trabalho e Educação: Ventrais Sindicais e Reestruturação Produtiva no Brasil. Rio de Janeiro: Ed. Quartet, 2002.

ZARIFIAN, P. Objetivo Competência: Por uma Nova Lógica. São Paulo: Ed. Atlas, 2001. 


\section{Dados completos de TODOS os autores:}

\section{Nome completo: Rejane Prevot Nascimento}

Filiação Institucional: Universidade do Grande Rio - UNIGRANRIO

Departamento: Programa de Pós-Graduação em Administração - Escola de Gestão e Negócios

Cargo Ocupado: Professor Adjunto Doutor

Endereço Completo para Correspondência: Rua da Lapa, 86, 9 andar. Centro, Rio de Janeiro, RJ. CEP.: 20021-180

Telefones para contato: 2125317764

e-mail: rejaneprevot@uol.com.br

\section{Nome Completo: Lidia Micaela Segre}

Filiação Institucional: Universidade do Grande Rio - UNIGRANRIO

Departamento: Programa de Pós-Graduação em Administração - Escola de Gestão e Negócios

Cargo Ocupado: Professor Adjunto Doutor

Endereço Completo para Correspondência: Rua da Lapa, 86, 9 andar. Centro, Rio de Janeiro, RJ. CEP.: 20021-180

Telefones para contato: 2125317764

e-mail:micaela@ms.microlink.com.br

Recebido para publicação em: 01/08/06

Aceito para publicação em: 14/09/06 